This is the peer reviewed version of the following article: Vecchiato, Riccardo, Favato, Giampiero, Di Maddaloni, Francesco and Do, Hang (2020) Foresight, cognition, and long-term performance : insights from the automotive industry and opportunities for future research. Futures \& Foresight Science, 2(1), e25., which has been published in final form at https://doi.org/10.1002/ffo2.25. This article may be used for non-commercial purposes in accordance with Wiley Terms and Conditions for Use of Self-Archived Versions. 


\title{
Foresight, cognition, and long-term performance: insights from the automotive industry and opportunities for future research
}

\begin{abstract}
We explore the relationship between foresight and managerial cognition and the contribution of foresight to the long-term performance of organizations facing major sources of uncertainty. Our research setting is the automotive industry, a compelling research setting for illustrating and reflecting upon the role of foresight in strategic decision making, as this industry is currently experiencing major drivers of change and technological discontinuities. We carefully examined the most recent empirical and theoretical works in the field of foresight, by conducting a thorough literature review. We found that scholars and practitioners increasingly emphasize the ability of foresight to change the mental models of senior managers and the role of such ability in the long-term adaptation to external changes. Overall, our study contributes to the development of a programmatic stream of research in the domain of foresight and future studies.
\end{abstract}

Keywords: Foresight; Forecasting; Managerial Cognition; Uncertainty; Automotive Industry.

Running Head: Foresight and Cognition 


\section{Introduction}

The pace of change of the business environment is a major concern for the companies of every country and industry. The increase of environmental change resulted in the increase of uncertainty and encouraged the reconsideration of both the processes of strategic decision making and the nature of decision making itself (Rohrbeck et al., 2015; Wright et al., 2013).

In this context, foresight is becoming a relevant trend in strategic management. Its rise to prominence has been driven by the failings of more traditional approaches, as a response to the difficulty of making appropriate and robust decisions in the face of environmental change (Vecchiato, 2015). Foresight is currently applied by many large firms in such diverse sectors as energy, automotive, telecommunications, and information technology as well as by many national and regional governments aiming at supporting the growth and international competitiveness of local firms (Coates et al., 2010; Porter et al., 2005; Vecchiato and Roveda, 2010).

As foresight has begun to spread across different firms of different industries, however, there is a need to carefully assess its benefits and contribution to the long-term performance of organizations. The increasing complexity and dynamism of the business environment and thereby the increasing difficulty to make reliable predictions raise the challenge of mutual learning and transfer of the best foresight practices (Rohrbeck et al., 2015). By doing so, managers can figure out which lessons are transferable from one company (and industry) to another.

The main objective of this paper is to promote a systematic inquiry into the field of foresight, by carefully examining the most recent empirical and theoretical works in the field. We conducted a thorough literature review with papers being assessed through validated quality criteria regarding their scope and outcomes. According to Tranfield et al. (2003, p. 215), we 
referred to quality assessment as "the appraisal of a study's internal validity and the degree to which its design, conduct and analysis have minimized biases and errors".

The first step of our literature review consisted in the identification of an initial list of keywords specific to the research objective of "investigating foresight and its contribution to the long-term performance of organizations in the face of the growing uncertainty of the business environment". An initial, provisional list of relevant keywords was refined through discussions with senior academics and industry practitioners. These key words included "foresight; forecasting; managerial cognition; uncertainty; performance; adaptation; learning; prediction; competitive advantage; strategic decision making". Afterwards, search strings were developed from the identified keywords with the help of the Boolean operator *AND*/*OR* to search and access the relevant literature. An academic database (i.e., ABI/INFORM) was searched for relevant publications due to its international coverage from main business journals. The results suggested that some of the retrieved publications appeared to be less relevant as the keywords only appeared once in the paper, or they were not the main focus. Moreover, only studies relevant to foresight in corporate organizations (versus the public sector) were selected.

Although this paper is theoretical in nature, we use an empirical case, i.e., the automotive industry, to illustrate our findings regarding the relationship between foresight and the long-term performance of organizations, i.e., the benefits of foresight and the challenges that decision makers face when trying to concretely achieve these benefits. The automotive industry is currently experiencing major drivers of change: we explore the current and forthcoming sources of uncertainty and then we apply the relevant lessons from recent research on foresight and related literature on strategic management in order to reflect upon the likely role of foresight in sustaining the long-term advantage of automotive makers. 
The contribution of this paper is twofold. First, it links foresight to a wide range of mainstream research fields in literature on strategic management, by highlighting connections and new issues to be explored. Second, it develops a research agenda that may lead to further theoretical and empirical work on the nature and impact of foresight upon strategic investment decisions under conditions of uncertainty. By doing so, we hope to foster the development of a programmatic stream of research in the domain of foresight and future studies.

The paper is structured as follows. First, we illustrate our conceptual model regarding foresight and its contribution to the long-term performance of organizations in uncertain environments, as it emerged from our literature review (section 2). We then focus on the automotive industry and illustrate key drivers of change and their implications for the sustainability of the competitive edge of current leaders (section 3). We then apply our conceptual model on foresight and long term performance on the automotive industry, in relation to each component of this model (section 4 and section 5). In the last sections we discuss our findings and point out opportunities for future research in the field (section 6 and section 7).

\section{Uncertainty, foresight, and performance: a conceptual framework}

In this section we present the conceptual framework emerging from our literature review. This framework builds upon four components: the relationship between uncertainty and strategic

decision making; cognition and the response to external changes; foresight and cognition; and decision makers biases and their role in foresight.

\subsection{Environmental uncertainty and strategic decision-making}


Environmental uncertainty has represented for a long time a major issue in strategic decision making, with early conceptualizations going back to such well-known scholars as Knight (1921), March and Simon (1958), Duncan (1972), and Lawrence and Lorsch (1967). Uncertainty regards the capability of corporate managers to identify external changes and their implications for their organizations Precisely, Milliken (1987) distinguished among three types of uncertainty that act together to determine the overall uncertainty faced by senior, middle, and frontline managers: these are 'state' uncertainty, 'effect' uncertainty, and 'response' uncertainty. 'State' uncertainty regards the difficulty to understand how drivers of change might evolve; 'effect' uncertainty regards the difficulty to anticipate their impact on the organization; 'response' uncertainty is the difficulty to figure out the response options available to the organization.

In order to cope with environmental uncertainty, studies in mainstream strategic management have developed around two fundamental approaches (Wiltbank e al., 2006): managers should either try harder to make more accurate predictions (rational strategies advocated by the "planning school") or be more flexible in order to adapt fast (adaptive strategies advocated by the "learning school").

Planning and prediction. According to the 'planning school' of strategic management, as uncertainty increases firms that work more diligently to predict the future evolution, impact and response of technological changes will outperform those firms that do not. Corporate managers should thereby analyse systematically their environment, generate plans and forecasts, rationally evaluate these forecasts and integrate them into their operations (Ansoff, 1991; Porter, 1980). Scholars in this tradition recognize that predictions might not be perfect because they are obviously difficult; however, formalized and systematic predictive approaches still represent the 
best way for remaining aligned with a changing environment, by allowing senior managers to benefit from emerging opportunities and threats.

Consistent with the core tenet of the planning school, specific practices and techniques have been developed and refined over time in corporate organizations in order to help managers cope with uncertainty. Scholars and practitioners have developed frameworks for analyzing risk management at the levels of innovation projects (De Meyer et al., 2002) and capital budgeting and capital structure policies (Bromiley, 1986; Graham and Harvey, 2001; Leland, 1998) and, more generally, explored what future-oriented techniques might enhance a firm's ability to make long-term strategic decisions at business and corporate levels (Courtney, 2001). Such techniques encompass two main tasks. The first concerns 'environmental scanning' to enable the detection of new events and drivers of change (Day and Shoemaker, 2006). Scholars in this field explore the environmental sectors that create greater strategic uncertainty for top executives, the frequency of scanning activities, and the sources of information about forthcoming changes and events (Hambrick, 1982). The second task concerns the investigation of the likely evolution of drivers of change, their consequences for the organization, and the most suitable responses. Some of the most popular techniques are product and technology roadmaps, scenarios and real options. Roadmaps consist of representations of interconnected nodes of major changes and events in selected fields of the external environment, such as science, technologies, or markets. The connecting links between nodes are the roadmaps themselves, illustrating their causal and temporal inter-relationships (Kostoff and Schaller, 2001; Phaal et al., 2004). Scenarios are focused descriptions of fundamentally different paths, presented in a script-like or narrative fashion, which tell coherent and credible stories leading to alternative futures (Schoemaker, 1993; Schwartz, 1991). Real options involve the application of financial options theory to investment 
decisions on real assets (McGrath et al., 2004): they emphasize that many initial investments (for example market tests, joint ventures, or operating licenses) create relevant opportunities that give the firm the chance (but not the obligation) to make subsequent follow-on investments (Dixit and Pindyck, 1994; Trigeorgis, 1996; Krychowski and Quelin, 2010).

Future-oriented techniques may largely differ in terms of complexity and sophistication. While some of them essentially rely on qualitative approaches and inputs, i.e. experts' opinions (qualitative techniques), others make extensive use of statistical and computational tools (quantitative techniques). Even for the same technique, e.g. scenarios, literature reveals the coexistence of several and at times contradictory definitions, principles and methodological guidelines (Bradfield et al., 2005). A further relevant distinction concerns the explorative vs. the normative nature (and use) of future oriented techniques and future studies (Porter et al., 2004).

The main rationale for the use of future-oriented techniques in the face of major sources of uncertainty is the achievement of "first mover advantages" (Liebermann and Montgomery, 1988; 1998). Such advantages stem from the development of superior technological skills, the leverage of customers' switching costs, or the pre-emption of scarce inputs or assets: the longer the lead time of competitive entry - and the longer the time a firm anticipates external changes compared with its rivals, the higher the likelihood of achieving first mover advantages.

Learning and experimentation. While the planning school emphasizes the role of prediction in uncertainty management, the 'learning school' prescribes to cope with environmental uncertainty by avoiding prediction as much as possible and focussing rather on responding to external changes and new events as they emerge (Quinn, 1980; Mintzberg, 1991). The main rationale for learning approaches is the acknowledgement that, while relatively accurate in the short term, the accuracy of any forecasting technique diminishes in the medium and long term as 
political, economic, social and technological changes interact in novel and unforeseeable ways (Galbraith and Merrill, 1996). The impossibility to make reliable enough predictions definitely represents an insurmountable barrier to strategic planning, by compromising its reliability and effectiveness. Drucker (1992) simply argues that "prediction is not a worthwhile managerial activity" and Hamel (2000) supports the idea that the best way to handle an uncertain future is to ignore it. In the same vein, Doz and Kosonen (2008) emphasize the use of adaptive approaches based on 'strategic agility' and 'organizational flexibility' rather than the systematic reliance on forecasting techniques.

Milliken (1987) characterized the process of learning on the basis of three main routines. The first consists in scanning the external environment in order to sense key trends, events and changes. The second consists in the seizing of the main threats and opportunities inherent in these changes. The third consists in taking actions in response to environmental changes. Such characterization of organizational learning builds on a classical observation drawn from behavioral studies, according to which firms are seen:

"as learning by encoding inferences from history into routines that guide behavior. The generic term 'routines' includes the forms, rules, procedures, conventions, strategies, and technologies around which organizations are constructed and through which they operate. It also includes the structure of beliefs, frameworks, paradigms, codes, cultures, and knowledge that buttress, elaborate, and contradict the formal routines. Routines are independent of the individual actors who execute them and are capable of surviving considerable turnover in individual actors (Levitt and March, 1988)."

Organizational routines evolve as a result of experience and interpretation of routines themselves on the basis of their historical outcomes: the likelihood that a routine will be used increases when it is associated with success in meeting a target and decreases when it is associated with failure (Cyert and March, 1963). 
According to the learning school, firms that minimize the use of predictive rationality and continuously experiment instead can benefit from late mover advantages that counterbalance or even considerably exceed the first mover advantages of pioneer firms that try to foresee and respond early to technological changes (Liebermann and Montgomery, 1988; 1998). When the imitation costs are lower than innovation costs, late movers may benefit from the opportunity to "free-ride" on first mover investments in a number of areas including R\&D, marketing and buyer education, post sale services. Furthermore, late mover can benefit from the resolution of technological and market uncertainty. Firms' size is a key issue on this regard: late movers that control complementary resources in marketing (e.g. brands, distribution channels) and production (e.g., facilities) might easily bridge the time gap with small-sized innovators or pioneer companies. Finally, late movers can benefit from the inertia and the vulnerability of first movers, in the case the latter ones get locked in a set of assets which ultimately proved to be not consistent with real evolution of customer demand.

\subsection{Uncertainty and cognition}

While some scholars focused on the approaches to strategic decision making in the face of uncertainty, some others explored the role of cognition and managerial beliefs (i.e., mental models and strategic assumptions) in directing responses to external changes and thereby competition outcomes in uncertain environments (Walsh 1995; Kaplan, 2008a).

Initial studies about cognition date back to the pioneering work of Kiesler and Sproull (1982). Subsequent research efforts focused on two cognitive processes that are relevant to strategic decision making, i.e., attention and interpretation (Weick \& Sutcliffe, 2007).

Regarding attention, Ocasio (1997) argues that "the ability of the firm to adapt successfully 
to a changing environment is conditional on whether the firm's procedural and communication channels focus the attention of the organizational decision-makers on an appropriate set of issues and answers." Empirical work has demonstrated that the attentional perspective can explain firms' strategies and actions, such as the speed of response to changes in the industry (Nadkarni and Barr, 2008), the timing of entry into a new product market (Eggers and Kaplan, 2009) and the ability to detect weak signals leading to a crisis (Rerup, 2009).

Regarding the cognitive process of interpretation, Daft and Weick (1984), Jackson and Dutton (1988), and Porac et al. (1995) explore the way managers make sense of the wide array of information they receive from the business environment. Scholars have also connected managerial interpretation to strategic actions, in relation to external changes such as new technologies and customer demand (Nadkarni and Narayanan, 2007; Thomas et al.,1993).

All these studies have traditionally emphasized the role of prior history in informing the mental models of senior managers, by showing that these models are the encoding of their past experiences, namely, their idiosyncratic individual histories, organizational experiences and industry affiliations. Precisely, according to Kaplan (2008a), managerial beliefs strongly depend on "previous experiences—including individual career histories, project experience, functional membership, position in the hierarchy — and contexts—including the firm, the industry and the prevailing technological paradigm." Prahalad and Bettis (1986) show that as senior managers work together, they create a shared understanding of technologies over time — or a "dominant logic" that is unique to the firm given its distinctive history. Similarly, through their industry affiliation, managers often develop a shared understanding of the relevant competitors (Porac et al. 1995). Overall, the idiosyncratic histories of the organizations and industries in which 
managers have operated engender an accumulation of knowledge that is the main source of their beliefs (Kaplan and Tripsas, 2008).

In changing and uncertain environments, the influence of prior history often increases the difficulty that decision makers face when seeking to broaden the scope of their search processes, often resulting in organizational inertia and poor performance. For instance, in the transition to digital imaging, Polaroid's commercialization strategy was driven and limited by beliefs inherent to the analog photography business model (Tripsas and Gavetti, 2000).

\subsection{Foresight and strategic decision making under uncertainty}

Since the early 2000s, strategic foresight emerged as a new approach to decision making that tried to revise traditional planning processes and, more important, the way future-oriented techniques are used in relation to the evolution and adaptation of the mental models of decision makers.

Within the foresight approach, the role of future-oriented techniques is not to anticipate the future as "it exactly will be" but to set the stage for a learning process which fosters adaptation and prepares for future challenges (Tsoukas and Shepherd, 2004; van der Heijden et al., 2002). Precisely, Rohrbeck et al. (2015) define foresight as "a practice that permits an organization to lay the foundation for a future competitive advantage", by helping managers to identify, observe and interpret trends and signals of change, anticipate what may happen in the future, gather necessary resources on time, and ultimately challenge conventional ideas. Foresight thus consists in the use of future-oriented techniques as a systematic process which enables decision makers to change the strategic beliefs (i.e., mental models) they inherit from their past experiences. The link between foresight and managerial cognition is particularly relevant to fully understand both the 
novelty of foresight and its likely benefits (Bowman, 2015; Vecchiato, 2019), by yielding a new perspective in the research field on cognition and, more generally, strategic decision making under uncertainty.

The technique of scenarios provides a compelling example in this regard (Phadnis et al., 2015). Scenario planning has been mostly used in corporate organizations as an approach aimed not at anticipating the future but rather at encouraging managers to explore strategic responses beyond the scope of their previous experiences and their established search processes. Scenarios are meant to increase organizational flexibility by providing managers with a "head start, as well as a conceptual framework within which to scan, encode, update, and understand the future as it unfolds" (Schoemaker 1993). Eisenhardt (1999) similarly highlights the "frame-breaking ability" of scenarios to "change the decision makers' assumptions about how the world works and compel them to reorganize their mental model of reality" (Wack 1985).

De Geus (1997) explains the capability of scenarios to change managerial beliefs as follows. Human brains constantly probe the conditions of the outside world and then immediately consider the actions that they can take, in a constant sequence, on alternative paths that lead to different futures. Different assumptions about the future can be remembered, often in great detail, exactly like memories of past events because human brains not only construct but also store anticipations about the future, which then become mental models, i.e., "memory of the future". The concept of "memory of the future" was originally introduced by Ingvar, (1985). Without a memory of the future, people would not be able to extract meaningful information from the enormous and random sensory noise to which their brains are continuously exposed in their changing environment:

You personally and your company are being bombarded by an overload of signals from the outside world. [...] The function of the memory of the future is to allow the brain to select 
those signals that are relevant for you. The test of relevance is your memory of the future. If a signal comes in, it passes through this memory of the future. If it finds a store in an alternative time path, meaning that it is relevant for you, then the signal is translated into data: it becomes information and then information becomes understanding. ${ }^{1}$

The core benefit of scenario planning consists in expanding the mental models of decision makers, i.e., their memory of the future, beyond the boundaries of their past experiences so that they can notice and make sense of a larger array of events in their external environment:

If you have only one possible alternative path into the future, you see-or hear-very little. This is the real importance of scenario planning. It stretches the time horizon from one or two years to ten or twenty years, and paradoxically, while increasing the time horizon, at the same time, in the present, it increases the power of perception. You hear more signals that are relevant to you. ${ }^{2}$

\subsection{Managerial biases in foresight}

While some scholars emphasized the effects of foresight on the mental models of senior managers, some others explored the role of managerial biases (i.e., distortions in judgements and decisions) in both the processes and outcomes of foresight (Konrad et al., 2012: Meissner and Wulf, 2013: Rowe et al., 2005). Precisely, the contributions from these scholars explored cognitive biases and identified the main areas of foresight in which biases are likely to materialize and affect the possible benefits of foresight. This work was significantly influenced by the research on cognitive psychology and decision-making that Kahneman and Tversky started in the '70s. According to this research, the ability of decision-makers to perform cognitive tasks is subject to limitations that originate from memory capacity and the nature of information processing. These limitations lead managers to be subject to systematic distortions in their

\footnotetext{
${ }^{1}$ Arie de Geus, keynote speech 'The Living Company_Long Term Thinking in a Changing Society,' presented at the In the Long Run Conference, Berlin, Germany, October 18, 2004. See In the Long Run, (2005), Burmsteir, K. and Neef, A. (Eds.). Oekom: Munich, Germany.

${ }^{2}$ Arie de Geus, ibidem.
} 
judgments and evaluation processes. Common managerial biases include overconfidence, framing, desirability biases, and planning fallacy (Kahneman and Tversky, 1974).

Overconfidence takes place when the confidence of decision makers in their assumptions about the future exceeds the actual accuracy and reliability of such assumptions (Simon and Houghton, 2003). Scholars have identified many negative outcomes due to the overconfidence bias. For example, Whyte et al. (1997) find that high confidence leads to an escalation of commitment to a losing course of action. Similarly, in a simulation study, Audia et al. (2000) found that managers who had experienced success in the past, and were therefore more confident, are more likely to stick to an original course of action when the environment they were operating in had changed. Akin to overconfidence, the framing bias describes a situation in which a cognitive task is deeply influenced by its initial description, so that equally legitimate but different task descriptions lead to severely different cognitive outcomes. The desirability bias takes place instead when new ideas, products or technologies are expected to offer solutions to unsolved issues and managers overestimate the probability of such future desirable developments (Echen et al., 2011). Finally planning fallacy is related to the tendency of managers to systematically overestimate how much they can achieve in a given time period, or underestimate the time needed to achieve a given result (Kahneman and Tversky, 1979). For instance, NewbyClark et al. (2000) found that senior managers tend to build up scenarios based on a progression of the present to the future and in doing so focus on the optimistic scenarios and disregard the pessimistic ones.

Overall, the work of these scholars suggests that the relationship between foresight and managerial beliefs is not linear as managerial beliefs themselves (and managerial biases about 
drivers of change in the external environment) affect the activities and outcomes of foresight, through an ongoing process (Bradfield, 2008).

Based on the four components we have described in this section of the paper, our literature review suggests the emergence of a conceptual framework on the relationship among uncertainty, foresight, strategic decision making, cognition, and long-term performance. In Figure 1 we illustrate this framework.

[Insert Figure 1 about here]

This conceptual framework summarizes the extant contributions of scholars and practitioners in relation to the role and outcomes of foresight. Precisely, the role of foresight is to support strategic decision making in the face of the growing uncertainty of the business environment. Foresight consists in the systematic analysis of drivers of change and their evolution and impact on the organization. Foresight is meant not to anticipate the future but to prepare the organization for the future, by changing the mental models that decision makers inherit from their previous history and helping them to overcome the inertia inherent in these beliefs. These likely benefits and outcomes, however, might be actually counterbalanced and jeopardized by such cognitive biases as overconfidence and planning fallacy.

In the remainder of the paper we apply our conceptual framework to the case of the automotive industry, by illustrating its implications and providing some clear recommendations for practitioners in the face of some major drivers of change that are going to affect (or are already affecting) this industry. 


\section{Environmental change and challenges to foresight: the case of the}

\section{automotive industry}

In the next few years the automotive industry is likely to undergo a significant transformation. The products and services that will be developed, the companies that provide these products and services and the consumers who buy them will probably be very different from today. The signs of this transformation are starting to show unequivocal: one example is represented by the rise (and decline?) of Tesla, the car brand focused on electric cars, which in the first semester of 2018 reached a market capitalization higher than incumbents like Ford and General Motors (and still in the second half of 2018 suffered from a considerable drop in its market value).

The main forces behind the deep restructuring of this industry are new technologies affecting all the activities of the value chain, from manufacturing to sale and post-sale services, from logistics to marketing. New scenarios are envisaged by industry experts in which cars will increasingly become digital hubs, as active parts of a real and broader mobility system with limited emissions and reduced pollution. ${ }^{3}$ The car of the future might be able not only to monitor its operating conditions in real time, but also to communicate with other vehicles and with an increasing number of intelligent road infrastructures. Such scenarios entail that car manufacturers are going to become more and more interconnected with startups and new major players from the ICT industry and propose new solutions and business models. New players entering the automotive business from the ICT sector include providers of software platforms and operating systems; providers of new value added applications, like entertainment and working on the move services; providers of smart devices and sensors for interconnected systems; companies specialized in the collection and real time elaboration of big data. 
Hereafter in this section we briefly illustrate some of the main technological and managerial changes behind the mid- and long-term evolution of the automotive industry.

Self-driving cars. Self-driving (or autonomous) cars are vehicles able to sense the external environment and navigate without human inputs. According to Elon Musk, CEO of Tesla, in the long run "nobody will buy a car that is not autonomous: owning a vehicle that does not drive alone will be like having a horse. You can keep it and use it for sentimental reasons, but not for daily use". It is not surprising thereby that Tesla, together with Google and Apple, is one of the international giants that are most committed to the development of self-driving cars. All these companies are investing millions of dollars in this technology - and established leaders in the automotive industry such as BMW, Audi, Volvo, Mercedes, Toyota, Nissan, Jaguar, Land Rover and FCA have similarly started to do so.

The self-driving car market is ultimately pushing a deep restructuring of both the ICT and automotive sectors. In 2017, Intel, the US giant of microprocessors, has paid \$15 billion to buy Mobileye, a major player in the development of vision technology for driver assistance systems. In 2016, Samsung took over Harman, a leading company in audio technology that produces domestic and automotive systems for $\$ 8$ billion; in the same year, SoftBank has invested $\$ 30$ billion into the acquisition of Arm Holdings, a British company active in the microchip market for smartphones and tablets with possible applications in the field of automobiles. Previously in 2013, Google bought Waze Mobile for $\$ 1.1$ billion, a startup developing a crowdsourced mobile-

\footnotetext{
${ }^{3}$ See for instance The Economist, The Future of Transportation, accessed on May $27^{\text {th }}, 2018$, available at https://thefutureishere.economist.com/transportation/blogs-future-transportation.html

${ }^{4}$ D. Bolton, The Indipendent, "Tesla CEO Elon Musk says that owning a non-autonomous car will be soon like 'owning a horse', November 4th, 2015, available at https://www.independent.co.uk/life-style/gadgets-and-tech/news/elon-musk-tesla-self-driving-autonomous-car-likeowning-a-horse-a6720816.html
} 
based road navigation application while Apple, again in 2013, put its hands on Prime Sense, a provider of sensory inputs.

Electric cars. In 2018, the electric car market has been expanding significantly, thanks to numerous plug-ins and eco-compatible car models, among which the Ford Focus, the Nissan Leaf and the Chevy Volt. Electric vehicles have generated a new ecosystem of partnerships between incumbent firms in the automotive industry and newcomers or startups from a number of different other sectors. Enel (a leading Italian manufacturer and distributor of electricity) and Nissan, for instance, have recently signed a partnership to propose "e-go All Inclusive", an integrated offer that provides Italian customers with electric cars for rental, domestic charging stations, and an app to locate them within the whole country. Remarkably, such offer contextually introduced a disruptive business model that bets on green technologies for reducing pollution in urban centers.

Car sharing and new patterns of mobility consumption. Car sharing is gradually evolving from a niche to a mass market. For instance, in Italy car sharing mobility is becoming more and more successful, boosting startups such as Urbi, a company that has developed a homonymous application aggregating the main urban and shared mobility systems, e.g., cars, bikes, scooters, taxi and Uber, the well-known global leading company for on-demand transport services. As a further example, in early 2017, the Europcar Group (a leading European car rental company) announced the acquisition of Guide Me, a car sharing company originally based in Milan, and started offering in Italy (as well as in many other European countries) car sharing services as an alternative to its mainstream rental services. Similarly Ford, through a 310 million fund, has financed 15 startups active in the sectors of car sharing and connected cars. 
Beyond the case of car sharing, new mobility patterns are becoming increasing popular. These new patterns involve users to focus on mobility services rather than automotive products, so pushing incumbent automotive firms to deeply revise the scope of their activities. For instance, in 2016, Toyota signed an agreement with Uber allowing the drivers of this company to purchase the vehicles of the Japanese group as part of a general leasing program. In 2016, Volkswagen also announced a $\$ 300$ million investment in Gett, a small Israeli startup offering a service very similar to that of Uber, while General Motors acquired a major stake of Lyft - Uber's competitor call taxi service.

Online sales. In the second half of the 2010s, the automotive market has been experiencing a noteworthy recovery thanks also to such an increasing trend as online sales. As an example, Alfa Romeo (part of the FCA group) on the occasion of the debut on Tmall, a platform of the Alibaba group, has sold 350 model cars Giulia limited edition "Milan" in less than 1 minute. In China, the largest world's automotive market, a growing number of customers are buying their cars online, prompting manufacturers to open virtual shops and partners with local e-commerce sites. ${ }^{5}$ This trend highlights the growing relevance of online trade for cars and, at the same, time, the changing role of dealers that are increasingly focusing their strategic efforts on assistance and post-sale services.

Smart manufacturing. The automotive sector has one of the highest levels of automation. New interconnected production systems are leading to increased safety and optimization of the use of materials, by continuously monitoring the activities performed by people and machines.

\footnotetext{
${ }^{5}$ Wang Y. Would You Buy A Car Online? Why Chinese Motorists Are Skipping The Dealership For Virtual Showrooms. Forbes, December $12^{\text {th }}, 2017$, available at https://www.forbes.com/sites/ywang/2017/12/12/would-youbuy-a-car-online-why-chinese-motorists-are-skipping-the-dealership-for-virtual-showrooms/\#178882153132
} 
New technologies and managerial solutions enhance as well energy saving in the field of fluidomechatronics engineering that, in turn, enhances energy recovery and allows the smart monitoring of industrial processes, with the double benefit of lower bills and preventive maintenance.

Artificial Intelligence. Artificial intelligence technologies and innovative applications will allow cars to become smarter and smarter, by enabling customers to use just voice commands to reply to emails or consult the apps on their smartphones, pay for refueling while sitting behind the wheel, receiving automatic notifications when a breakdown is occurring, or receive alerts if other users are exceeding speed limits when driving their cars. Even today, incumbent firms in the automotive industry are using artificial intelligence applications in order to redesign all the activities of their value chain, from design to manufacturing, from R\&D to marketing. For instance, IBM and General Motors have entered into a partnership for the development of a platform which will automatically connect drivers with the companies providing the services they require in the proximity of their cars. BMW and Microsoft are also developing together a new tool for travel management while Ford has recently acquired for \$1 billion Argo AI, a startup developing artificial intelligence software.

\section{Framing the uncertainty of the automotive industry}

All the above technological changes contribute to considerably increasing the overall uncertainty that the decision makers of incumbent automotive firms are facing as they try to sustain their competitive edge in the long run.

'State' uncertainty specifically regards the difficulty of automotive firms to understand how drivers of change might evolve. For instance, in the case of the technology of self-driving cars, 
industry experts identified six different levels of autonomy (SAE International, 2014). ${ }^{6}$ These levels are: "Level 0" (i.e., cars have no autonomous features and drivers fully control acceleration, braking and steering at all times); "Level 1" (driver assistance - cars have some autonomous features: in certain situations, such as cruise control and parking, cars can take control of the steering wheel or the pedals); "Level 2" (Partial automation, 'hands off wheel sometimes': cars can take over accelerating, braking and steering, but only under certain conditions, as drivers must continuously monitor the self-driving systems and be prepared to intervene immediately if these systems fail to respond properly); "Level 3" (Conditional automation, 'hands off wheel and eyes off road - sometimes': cars can fully take over the driving responsibilities under certain conditions, and drivers can focus their attention on non-driving tasks. In particular, cars can decide when to change lanes, brake in an emergency, and respond to incidents on the road); "Level 4" (High-level automation, 'Hands, off, eyes off, mind off sometimes': Level 4 autonomy on a vehicle is the same as in the case of Level 3, but cars can drive themselves under specific circumstances, and a human driver is not required to take control at these times); and "Level 5" (Full automation: no human attention, or indeed a human driver, is required and even a steering wheel is optional). Coping with the state uncertainty of self-driving car requires exactly to anticipate which level of autonomy customers will demand in the long run, or perhaps the emergence of different market niches where customers demand different levels of autonomy (and if so: what will the size of each niche be?).

'Effect' uncertainty entails that even if the senior managers of automotive firms predict exactly the Level of autonomy of future cars (e.g., Level 5), they still need to anticipate the

\footnotetext{
${ }^{6}$ SAE International. 2014. Automated Driving Levels of Driving Automation are defined in New SAE International Standard J3016. Available at: http://www.sae.org/misc/pdfs/automated_driving.pdf.
} 
effects of this Level on their organization. For instance, in the case of Level 5: what will be the implications for business model, i.e., will future market leaders make most of their profits by selling cars or mobility services? What kind of services will customers demand while being driven (leisure, work, etc.)?. What will be the future industry value chain, i.e., who will enter the business (e.g., software companies providing the artificial intelligence tools driving the cars or the leisure services entertaining the customers; public or private organizations monitoring the traffic and governing the infrastructure, etc.) and what will be their role? What will be the core technological skills (e.g., mechanical, software, logistics) required for achieving a sustainable competitive advantage?

Finally, 'response' uncertainty requires the senior managers of automotive firms to address the following questions: how can they develop the software skills they require? Should they develop these technologies internally, acquire software start-ups, or partner with current software leaders (e.g., Google or Apple) or with other automotive makers? More generally, what new core technologies/competences should be kept internal and which ones should (or must) be outsourced?

\section{Foresight and cognition in the automotive industry: recommendations for}

\section{practice}

In order to address the likely evolution of autonomous and electric cars, their consequences for the organization, and the most suitable responses, the senior managers of leading automotive firms can choose among such techniques as product and technology roadmaps, scenarios, and Delphi - among others. Precisely, they can use roadmaps to represent, as interconnected nodes, the major technological changes and events affecting the automotive industry. The connecting 
links between the nodes would provide the roadmaps themselves, by illustrating the causal and temporal inter-relationships among technological and market changes. Scenarios would allow the senior managers of automotive firms to build focused descriptions of alternative stories depicting the future evolution of the industry. Finally, the Delphi technique would involve a huge number of experts and decision makers within (and outside) an automotive company and lead them to answer a structured questionnaire about autonomous cars, electric cars, new consumption patterns, etc., on two or more rounds. After each round, senior managers (and the other participants) can get a summary of average forecasts and the reasons for such forecasts and can then be allowed to revise their early answers in the light of this feedback, until a final consensus is reached.

Whatever the technique being chosen, however, the relationship among foresight, managerial cognition, and strategic decision making under uncertainty - as illustrated in Figure 1 - has relevant implications for the use of foresight techniques and processes. The managers of established automotive leaders should design, implement, and ultimately evaluate their foresight efforts in relation to the twofold objective of: i) changing the mental models they have developed through the previous history of the industry, and ii) reacting - focusing and interpreting - more promptly and effectively to the technological shifts that are affecting their business. At the same time, the managers of leading automotive firms should avoid the risk of locking themselves in the new beliefs that they develop through foresight.

\subsection{Using foresight to evolve mental models and enhance adaptation}

The decision makers of automotive firms should apply techniques like scenarios, Delphi, or roadmapping in order to systematically investigate alternative patterns of evolution of self- 
driving cars, electric cars, artificial intelligence applications, etc., the implications for their organizations, and the response options. As they envisage new patterns of evolution that represent a discontinuity from the previous history of their industry, decision makers can "store" these discontinuous patterns in their memories, making sense of them, and eventually build new memories of the future. These memories are not aimed to anticipate the actual future of the automotive industry (i.e., the ultimate state of self-driving cars, electric cars, artificial intelligence applications, etc.) but to help managers to recognize the future as soon as it starts materializing. In this way, automotive firms should achieve significant first mover advantages over rivals, through the timely (but not early) development of new technological skills, the pre-emption of scarce asses, and the shaping of customers' perceptual space.

Let's consider the case of the major technological discontinuity and source of uncertainty of self-driving (autonomous) cars. Using foresight to cope with such discontinuity means to systematically investigate all the alternative six levels of autonomy identified by industry experts (described in the previous sections of this paper). While Level 0 cars (cars with no autonomous features) represents the continuation of the past state of the automotive industry, the other levels (in particular, the Level 5 - fully autonomous cars) represent a completely different future. Techniques like scenarios or roadmapping can help decision makers to fully grasp the disruptive nature of Level 5 cars, by giving them the concrete opportunity to express and share their information and opinions about future barriers and enablers. Furthermore, such techniques can help decision makers to systematically think about the implications for their organizations of each level of autonomy, i.e., the rise of new firms coming from other industries - like Google and Apple - or the establishment of new business models based on the provision of mobility services rather than cars (i.e., Level 5 vs. traditional Level 0 autonomous cars). Finally, scenarios, 
roadmapping, and similar foresight techniques can help decision makers to systematically think about the resources they need for each level of autonomous cars, like traditional mechanical and engineering skills in the case of Level 0 cars vs. software technologies and artificial intelligence applications in the case of Level 5 cars.

Each scenario and/or roadmap which relates to a specific level of autonomous cars contributes to expanding the cognitive maps of decision makers, being a new vision of the future that (according to de Geus - see previous quotes) increases their "power of perception" and ultimately their capability to notice and interpret external signals. Examples of weak signals anticipating the eventual rise of any of the 6 levels of autonomous cars include approvals of governmental authorities, results of first experimentations and pilot tests, feedback about the compatibility/integration of different technologies (e.g., sensors, cameras, radar and data analytics, etc.). Roadmaps and/or scenarios then enable decision makers to react accordingly, by timely implementing the response options they have already figured out through the roadmaps/scenarios themselves.

The first automotive firms to perceive the exact level of autonomy of future cars can benefit from the timely development of the new technologies (e.g., software) required for such products and can thus outperform their rivals by means of patents, learning curve effects and, more generally, superior technological capabilities. Equally important, the first firms that interpret correctly the evolution, effect, and response to self-driving cars can timely develop a set of superior organizational capabilities in marketing and production (e.g., smart manufacturing plants). Similarly to technological skills, such marketing and production capabilities are likely to involve as well learning curve effects. Furthermore, the first firms that provide autonomous cars might create significant customers' switching costs that prevent the future entry of late movers. 
These witching costs stem from initial transaction costs or investments that customers make into the autonomous cars of first movers, like user interface and other software application products. As customers adapt over time to the characteristics of the user interfaces of the early providers of autonomous cars, they will eventually find it costly and uneasy to switch to the software products of other, late mover companies. Finally, the first firms that provide self-driving electric cars might gain a sound advantage over late movers by pre-empting the access to scarce inputs assets, like filling stations or certain components of batteries. Scarce inputs might also include customers' perceptual space.

Incumbent automotive makers can also pursue late mover advantages for benefiting from drivers of change - instead of first mover advantages. Incumbent firms control complementary resources in marketing (e.g. brands, distribution channels) and production (e.g., facilities) that reduce the need for first mover strategies and thus, apparently, for foresight. These resources enable incumbent firms to wait until uncertainty reduces: they can move late and still bridge the time gap with start-ups that pioneer new technologies and markets. (This has been the case for instance of the electric car, as established players like General Motors, BMW and Daimler let a start-up - i.e., Tesla - to initially pioneer and bear the risk for this new technology.) On the other hand, major drivers of change like autonomous cars are hardly compatible with the beliefs that the decision makers of incumbent automotive firms have inherited from their prior history (e.g., boundaries of the business ecosystem, key service features, business models). The challenge of altering the strategic beliefs of the managers of these firms is much more severe than in the case of the managers of start-up firms. The managers of incumbent automotive firms thereby should extensively use foresight - even more than the managers of start-ups - to renew their dominant logic and sharpen their capability to fully assess (i.e., sense and react) the evolution and impact of 
new technologies like autonomous cars. Only in this way, incumbent automotive firms can become aware of the first mover advantages or late mover advantages that are actually available to them - and ultimately make an informed choice about the right time for investing in new markets and technologies.

\subsection{Coping with the biases and drawbacks of foresight}

Our conceptual model highlights not only the benefits but also the likely possible pitfalls of foresight. While the senior managers of automotive firms can use foresight for changing their dominant beliefs and increase the chances to adapt quickly to external changes, they should be aware of the risk of becoming overconfident in their new beliefs and commit (too) early to a specific scenario of roadmap. Similarly, the senior managers of automotive firms can be affected by desirability bias as they overestimate the probability of future desirable developments, e.g., a new product or service. Furthermore, senior managers might be affected by planning fallacy and tend to overestimate how much they can achieve in a given time period or underestimate the time needed to achieve a given result, by focusing on the optimistic scenarios and disregarding the pessimistic ones. Overall, overconfidence, desirability bias, and planning fallacy can lead the managers of incumbent automotive firms to invest early in a new technology or business idea and expose themselves to the risk of locking in the wrong future. For instance, overconfident automotive makers that early develop a technological infrastructure for the Level 5 autonomous

vehicles (or whatever other level they desire) can find such infrastructure and the massive related investments completely useless if mainstream customers eventually opt for more conservative Level 2 or Level 3 autonomous cars. These firms might be affected by inertia and become more vulnerable, by locking themselves in a set of assets which can ultimately doom them to fail. The 
same cognitive biases might affect not only the decision makers of incumbent automotive firms but also those of newcomers, e.g., large software firms or start-ups.

Overall, if foresight processes and techniques fail to anticipate future sources of competitive advantage, the new beliefs of decision makers are likely to become a source of inertia rather than adaptation. Previous scholars focused on the capabilities (e.g., technologies, products and marketing assets) that firms develop according to their early predictions and strategic plans and emphasized that these capabilities often become sources of inertia (Liebermann and Montgomery, 1988; Mintzberg, 1990). However, firms that rely on foresight might fail to adapt to their changing environment not just due to the new capabilities that they early develop but rather because of the new managerial beliefs that foresight informs. The key issue in foresight is the capability to distinguish beliefs about the future that are correct (i.e., consistent with future competitive outcomes) and will facilitate adaptation from beliefs that are incorrect and will increase inertia instead.

In this regard, previous scholars have emphasized that strategies that effectively lead to adaptation should combine analytical efforts with continuous experimentation (Grant, 2003; Teece, 2007). Our research builds upon this work by strengthening the recommendation to generate and experiment with different futures rather than to select and commit early to only one future. Experimentation with alternative futures - e.g., with all the six level of autonomous cars can help managers to make exactly the distinction between correct beliefs and incorrect beliefs about future sources of competitive advantage.

The integration and contextual use of different foresight techniques might be very helpful for this purpose. For instance, research on real options has shown that this foresight technique provides an effective framework for the systematic generation and evaluation of alternative 
investment decisions (McGrath et al., 2004). We suggest that future research efforts focus on real options and, in particular, the combination of real options with scenarios as a valuable foresight approach that fosters the flexibility of managers' mental models about future sources of competitive advantage (Favato and Vecchiato, 2017). In the automotive industry, the combined use of scenarios and real options should be aimed to reduce the risk of betting on the wrong future while still giving firms the opportunity to achieve first-mover advantages.

More generally, in order to mitigate the biases inherent in foresight, we recommend that automotive firms adopt a multidisciplinary perspective and involve a wide range of outside stakeholders, by increasing the diversity of participants in foresight.

\section{Discussion and conclusions}

By combining research on foresight with research on cognition, our work underlines the benefits and, at the same time, the possible pitfalls stemming from to the relationship between foresight and managerial beliefs. We explore the role of foresight in strategic decision making and uncertainty management, by focusing on the relationship among foresight, managerial cognition, and long-term performance. Although this paper is theoretical in nature, we illustrate our insights through the empirical analysis of the automotive industry. We draw from different research streams: the first is literature on environmental uncertainty; the second is literature on strategic planning and learning; the third is literature on cognition. Overall, our work offers interesting opportunities for scholars who aim at deepening our understanding of the linkages between these research streams and the capability of organizations to cope with the growing turbulence of the business environment. 
Foresight has been receiving increasing attention by both scholars and practitioners, as evidenced by the increasing number of publications (i.e., journal papers, special issues) in the field. However, some skepticism arose in the academic community regarding the theoretical foundations and effectiveness of foresight, mostly in relation to traditional forecasting techniques (Bradley Mackey and Costanzo, 2009; Wiltbank et al., 2006). Therefore, a reconsideration of the nature of corporate foresight efforts and their contribution to long term performance is required. We propose this work on corporate foresight as a springboard which might serve to investigate further several important issues that have remained so far unresolved - a least partially - from both an academic and managerial perspective. These issues regard, first of all, the possible benefits of foresight and the main challenges to the concrete achievement of these benefits.

Our main contribution concerns the relationships among foresight, managerial cognition, and adaptation vs. inertia. On the one hand, we support the core tenet of the planning school - that an organization should try hard to predict changes and new events. On the other hand, we emphasize that the ultimate objective of foresight should not be the anticipation of the future per se but rather the change of the mental models that decision makers inherit from their past experiences. Foresight can thus help organizations to cope with the inertia that stem from prior history and enable decision makers to react more promptly and effectively to external events. Precisely, by addressing the future state of drivers of change ('state uncertainty'), foresight serves as microfoundation of the capability of decision makers to better interpret the evolution of these drivers. By addressing the future effects of external changes ('effect' uncertainty), foresight serves as microfoundation of the capability of decision makers to better interpret their impact on the value chain and the sources of competitive advantage. Finally, by addressing the response 
options to external changes ('response' uncertainty), foresight serves as microfoundation of the capability of decision makers to search for and develop new resources and organizational skills. At the same time, managers should be aware of the possible biases in foresight that can affect the ultimate capability of managers themselves to identify and adapt to external changes, by designing their foresight efforts in a way that mitigates these biases. As they explore further the relationship between foresight and managerial beliefs, joint efforts of scholars and practitioners can improve foresight by increasing our understanding of these biases and improving our capability to manage them (Vecchiato, 2015). In particular, previous work of scholars has showed that leading automotive firms like Audi and Daimler have been extensively engaged in foresight (Hofmann, 2015; Ruff, 2015). We suggest the automotive sector and especially these firms represent a compelling research setting for further expanding our understanding of the relationship between foresight and managerial cognition and thus the benefits and pitfalls of foresight. 


\section{References}

Ansoff, H.I. (1991), Critique of Henry Mintzberg's 'The design school': reconsidering the basic premises of strategic management, Strategic Management Journal, 12, 449-461.

Audia, P.G., Locke, E.A. and Smith, K.G. (2000). The paradox of success, Academy of Management Journal, 43, 837-53.

Bowman, G. (2016).The Practice of Scenario Planning: An Analysis of Inter- and Intra-organizational Strategizing. British Management Journal, 27, 77 - 96.

Bradfield, R., Wright, G., Burt, G., Cairns, G., and Van Der Heijden, K. (2005), The origins and evolution of scenario techniques in long range business planning, Futures, 37, 795 - 812.

Bradfiled, R.M. (2008). Cognitive Barriers in the Scenario Development Process. Advances in Developing human Resources, 2, 198 -215.

Bradley MacKay, R. and Costanzo, L.A. (2009), Introduction, in Bradley MacKay, R. and Costanzo, L.A. (Eds.), Handbook of Research on Strategic Foresight, Edward Elgar, Cheltenham, UK, 1-12.

Bromiley, P. (1986), Corporate Capital Investment: A Behavioural Approach. Cambridge University Press, New York.

Coates, J., Durance, P. and Godet, M. (Eds.), (2010), Strategic Foresight issue: Introduction, Technological Forecasting and Social Change Special Issue, 77, 1423-1425.

Courtney, H. (2001), 20/20 Foresight: Crafting Strategy in an Uncertain World, Harvard Business School Press, Boston, MA.

Cyert, R.M. and March, J.C. (1963). A Behavioural Theory of the Firm, Prentice-Hall, Englewood Cliffs.

Daft, R.L. and Weick, K.E. (1984), Toward a model of organizations as interpretation systems, Academy of Management Review, 9, 284-295.

Day, G.S. and Schoemaker, P.J.H. (2006). Peripheral Vision. Harvard Business School Press, Boston, MA.

de Geus, A. (1997). The living company. Harvard Business School Press, Boston, MA.

De Meyer, A., Loch, C.H. and Pich, M.T. (2002), Managing project uncertainty: from variation to chaos", Sloan Management Review, 43, 60-67.

Dixit, A.K. and Pindyck, R.S. (1994). Investment under uncertainty. Princeton University Press: Princeton, NJ.

Doz, Y. and Kosonen, M. (2008), Fast Strategy: How Strategic Agility Will Help You Stay Ahead of the Game, Wharton School Publishing, Philadelphia.

Drucker, P. (1992), The new society of organizations. Harvard Business Review, 72, 95 - 104.

Duncan, R.B. (1972), Characteristics of organizational environments and perceived environmental uncertainty, Administrative Science Quarterly, 17, 313-327. 
Echen P., Gnatzy T., von der Gracht H.A. (2011) Desirability in foresight. Consequences for decision quality based on Delphi results. Technological Forecasting and Social Change, 78, 1654-1670.

Eggers, J.P. and Kaplan, S. (2009). Cognition and renewal: Comparing CEO and organizational effects on incumbent adaptation to technical change, Organization Science, 20, 461-477.

Eisenhardt, K.M. (1999), Strategy as strategic decision making, Sloan Management Review, 40, $65-72$.

Faley, L. and Randall, R. (1998), Learning From the Future. John Willey \& Sons: New York.

Favato, G., Vecchiato, R. (2017). Embedding real options in scenario planning: a new methodological approach. Technological Forecasting and Social Change, 124, 135 -149.

Fink, A., Siebe, A. and Kuhle J.P. (2004), How scenarios support strategic early warning processes", foresight, 6, 173 - 185.

Galbraith, C.S. and Merrill, G.B. (1996), The Politics of Forecasting: Managing the Truth, California Management Review, 38, 29-43.

Graham, J. R. and Harvey, C.R. (2001), The theory and practice of corporate finance: evidence from the field, Journal of Financial Economics, 60, 187-243.

Grant, R.M. (2003), Strategic planning in a turbulent environment: evidence from the oil majors, Strategic Management Journal, 24, 491-517.

Hambrick, D.C. (1982), "Environmental scanning and organizational strategy", Strategic Management Journal, 3, 159-174.

Hamel, G. (2000), Leading the revolution, Harvard Business School Press, Boston MA.

Hofmann, R. (2015). Visionary competence for long-term development of brands, products, and services: the trend receiver concept and its first applications at Audi. Technological Forecasting and Social Change, 101, 147-164.

Ingvar, D.H. (1985), Memory of the future: an essay on the temporal organization of conscious awareness, Human Neurobiology, 4, 127-136.

Jackson, S.E. and Dutton, J.E. (1988), Discerning threats and opportunities, Administrative Science Quarterly, 33, 370-387.

Kahneman, D., Tversky, A. (1974). Judgement under uncertainty: heuristics and biases. Science $185,1124-1131$.

Kahneman, D., Tversky, A. (1979). Intuitive prediction: Biases and corrective procedures. TIMS Studies in Management Science, 12, 313-327.

Kaplan, S. (2008a), Framing contests: strategy making under uncertainty, Organization Science, $19,729-752$

Kaplan, S. and Tripsas, M. (2008), Thinking about technology: applying a cognitive lens to technical change, Research Policy, 37, 790-805.

Kiesler, S. and Sproull, L. (1982). Managerial response to changing environments: perspectives on problem sensing from social cognition, Administrative Science Quarterly, 27, 548-570. 
Knight, F.H. (1921), Risk, Uncertainty, and Profit, Hart, Schaffner \& Marx, New York.

Konrad K., Markard J., Ruef A. (2012) Strategic responses to fuel cell hype and disappointment. Technological Forecasting and Social Change. 79(6), 1084-1098.

Kostoff, R.N. and Schaller. R.R. (2001), Science and Technology Roadmaps”, IEEE Transactions on Engineering Management, 48, 132-143.

Krychowski C. and Quelin, B. (2010), Real Options and Strategic Investment Decisions: Can They Be of Use to Scholars? Academy of Management Perspectives, 24, 65-78

Lawrence, P.R. and Lorsch, J.W. (1967), Organization and Environment, Harvard University Press, Cambridge, MA.

Leland, H. E. (1998), Agency costs, risk management, and capital structure", The Journal of Finance, 53, 1213-1243.

Levitt, B., March, J.C. (1988). Organizational Learning. Annual Review of Sociology, 14, 319340.

Lieberman, M.B. and Montgomery, D.B. (1998), First-mover (Dis)advantages: Retrospective and Link with the Resource-Based View, Strategic Management Journal, 9, 1111-1125.

Lieberman, M.B. and Montgomery D.B. (1988), First-mover advantages, Strategic Management Journal, 9, 41-58.

March, J.G. and Simon, H.A. (1958), Organizations, McGraw-Hill, New York.

McGrath, R.G., Ferrier, W.J. and Mendelow, A.L. (2004), Real options as engines of choice and heterogeneity, Academy of Management Review, 29, 86-101.

Meissner P., Wulf T. (2013) Cognitive benefits of scenario planning: Its impact on biases and decision quality. Technological Forecasting and Social Change, 80, 801-814.

Milliken, F.J. (1987), Three types of perceived uncertainty about the environment: state, effect, and response uncertainty, Academy of Management Review, 12, 133-143.

Mintzberg, H. (1990), The design school: reconsidering the basic premises of strategic management" Strategic Management Journal, 11, 171-195.

Nadkarni, S. and Barr, P.S (2008). Environmental context, managerial cognition, and strategic action: An integrated view, Strategic Management Journal, 29, 1395-1427.

Nadkarni, S., Narayanan, V.K. (2007), The evolution of collective strategy frames in high- and low-velocity industries, Organization Science, 18, 688-710.

Newby-Clark I.R., Ross M., Buehler R., Griffin D.W. (2000) People focus on optimistic scenarios and disregard pessimistic scenario when predicting task completion times. Journal of Experimental Psychology Applied, 6, 171-182.

Ocasio, W. (1997). Towards an attention-based view of the firm, Strategic Management Journal, 18, 187-206.

Phaal, R., Farrukh, C.J.P., and Probert, D.R. (2004). Technology roadmapping - A planning framework for evolution and revolution, Technological Forecasting and Social Change, 71, $5-26$. 
Phadnis, S., Caplice, C., Sheffi, Y. and Singh, M. (2015). Effect of scenario planning on field experts' judgement of long-range investment decisions, Strategic Management Journal, 36, $1401-1411$

Porac, J. F., Thomas, H, Wilson, F., Paton, D. and Kanfer, A. (1995), Rivalry and the industry model of Scottish knitwear producers, Administrative Science Quarterly, 40, 203-227.

Porter, A.L., Ashton, B., Clar, G., Coates, J.F., Cuhls, K., Cunningham, S.W., Ducatel, K., Van der Duin, P., Georghiou, L., Gordon, T., Linstone, H., Marchau, V., Massari, G., Miles, I., Mogee, M., Salo, A., Scapolo, F., Smits, R., Thissen, W. (2004), Technology futures analysis: toward integration of the field and new methods, Technological Forecasting and Social Change, 71, 287-303.

Porter, M.E. (1980), Competitive Strategy, Free Press, New York.

Prahalad, C.K. and Bettis, R.A. (1986). The dominant logic: a new linkage between diversity and performance, Strategic Management Journal, 76, 485-501.

Quinn, J.B. (1980), Strategies for change: Logical incrementalism. Dow-Jones-Irwin, Homewood, IL.

Ratcliffe, J. (2002), Scenario planning: strategic interviews and conversations, foresight, 4, 1930 .

Rerup, C. (2009). Attentional triangulation: Learning from unexpected rare crises, Organization Science, 20, 876-893.

Rohrbeck, R., Battistella, C. and Huizingh. E. (2015), Corporate foresight: An emerging field with a rich tradition. Technological Forecasting and Social Change, 101, 1-9.

Rowe G., Wright G., Mc Call A. (2005) Judgment change during Delphi-like procedures. The role of majority influence, expertise, and confidence. Technological Forecasting and Social Change, 72, 377-399.

Ruff, F. (2015), The advanced role of corporate foresight in innovation and strategic management - reflections on practical experiences from the automotive industry, Technological Forecasting and Social Change, 101, 37-48.

Schoemaker, P.J.H. (1993). Multiple scenario development: its conceptual and behavioural foundation, Strategic Management Journal, 14, 193-213.

Schwartz, P. (1991). The art of the long view: Planning for the future in an uncertain world. Doubleday Currency, New York.

Simon, M. and Houghton, S.M. (2003). The relationship between overconfidence and the introduction of risky products: evidence from a field study, Academy of Management Journal, 46, 139 - 149.

Teece, D.J. (2007), Explicating dynamic capabilities: the nature and microfoundations of (sustainable) enterprise performance, Strategic Management Journal, 28, 1319-1350.

Thomas, J.B., Clark, S.M. and Gioia, D.A. (1993), Strategic sensemaking and organizational performance: Linkages among scanning, interpretation, action, and outcomes, Academy of Management Journal, 36, 239270. 
Tranfield, D., Denyer, D., and Smart, P. (2003). Towards a methodology for developing evidence-informed management knowledge by means of systematic review. British Journal of Management, 14, 207-222.

Trigeorgis, L. (1996), Real options. Managerial flexibility and strategy in resource allocation. MIT Press, Cambridge, MA.

Tripsas, M. and Gavetti, G. (2000), Capabilities, cognition, and inertia: evidence from digital imaging, Strategic Management Journal, 21, 1147-1162.

Tsoukas, H. and Shepherd, J. (2004), Introduction: organization and the future, from forecasting to foresight, in Tsoukas, H. and Shepherd, J. (Eds.) Managing the Future: Foresight in the Knowledge Economy, Blackwell, London, 1-19.

van der Heijden, K., Bradfield, R., Burt, G., Crains, G. and Wright, G. (2002). The Sixth Sense: Accelerating Organisational Learning with Scenarios, Wiley, Chichester.

Vecchiato, R. (2012), Environmental uncertainty, foresight and strategic decision making: an integrated study. Technological Forecasting and Social Change, 79, 436-447.

Vecchiato, R. (2015), Creating value through foresight: First mover advantages and strategic agility. Technological Forecasting and Social Change, 101, 25-36.

Vecchiato, R. (2019). Scenario planning, cognition, and strategic investment decisions in a turbulent environment. Long Range Planning, forthcoming.

Vecchiato, R. and Roveda, C. (2010), Strategic foresight in corporate organizations: assessing the effect and response uncertainty of technology and social drivers of change, Technological Forecasting and Social Change, 77, 1527-1539.

Wack, P. (1985), Scenarios: Uncharted waters ahead, Harvard Business Review, 63, 73-89.

Walsh, J.P., (1995). Managerial and organizational cognition: Notes from a trip down memory lane, Organization Science, 6, 280-321.

Weick, K.E. and Sutcliffe, K.M. (2006). Mindfulness and the quality of organizational attention. Organization Science, 17, 514-524.

Whyte, G., Saks, A.M. and Hook, S. (1997). When success breeds failure: the role of selfefficacy in escalating commitment to a losing course of action, Journal of Organizational Behavior, 18, 415-32.

Wiltbank, R., Dew, N., Read, S. and Sarasvathy, S.D. (2006), What to do next? The case for nonpredictive strategy, Strategic Management Journal, 27, 981-998.

Wright, G., Bradfield, R. and Cairns, G. (2013). Does the intuitive logics method - and its recent enhancements - produce "effective" scenarios? Technological Forecasting and Social Change, 80, 631- 642 . 




Figure 1. Relationship among foresight, decision making, strategic beliefs, and long-term performance under uncertainty 